Gut, 1971, 12, 585-591

\title{
Portal venous injection in the rat
}

\author{
L. H. BLUMGART, K. G. LEACH, M. S. F. McLACHLAN, S. SEAGER, AND \\ C. J. RYAN
}

From the Departments of Surgery, Medical Physics, and Diagnostic Radiology, the Welsh National School of Medicine, Cardiff Royal Infirmary

SUMMARY A technique for subcutaneous transposition of the spleen in the rat is described. The preparation has been developed as a reliable means of transplenic portal injection.

It has been shown that different substances injected into the pulp of the transposed spleen are cleared and not pooled in the organ.

The development of porta-systemic venous communications has been demonstrated and their detection radiologically and by isotope techniques is illustrated.

It is suggested that the technique outlined in this communication may be of value in the study of the portal circulation, the function of the liver, and in the investigation of drug action.

If adequate porta-systemic venous connexions are present the portal vein can be tied above its splenic tributary and the animal will survive. The method offers a simple means of porta-systemic diversion in the rat.

A method for easy and repeated introduction of solutions into the portal circulation of an experimental animal would be of value in the study of portal haemodynamics. It would also facilitate the investigation of the metabolism of drugs, the mode of action of hepatotoxic agents, and the assessment of drugs used in the treatment of diseases affecting the liver.

Recently Bengmark, Börjesson, Olin, Sakuma, and Vosmic (1970) reported a method for subcutaneous splenic transposition in the rat and hoped to use the preparation for transplenic portal injection. However, they found that a rich network of subcutaneous porta-systemic communications developed within three weeks. This collateral circulation was so extensive that it was concluded that the method was of limited value as a technique for portal injection. We have developed a technique that differs somewhat from that described by Bengmark et al (1970) and we present it as a reliable means of transplenic portal injection.

\section{Methods and Materials}

Male Sprague-Dawley rats weighing between 250 and $350 \mathrm{~g}$ were anaesthetized by ether inhalation or intraperitoneal injection of veterinary nembutal $\left(0.07 \mathrm{ml}\right.$ per $100 \mathrm{~g}$ body weight $\left.{ }^{1}\right)$.

$160 \mathrm{mg} / \mathrm{ml}$.

Received for publication 6 April 1971.

\section{SURGICAL PROCEDURES}

\section{Subcutaneous splenic transposition}

A midline incision was made and the skin on the left side of the abdominal wall was gently mobilized from the underlying muscle taking care to avoid bleeding. The abdomen was opened by incising the linea alba and the spleen delivered through the abdominal wound. The fine peritoneal attachments between the spleen and the stomach were divided leaving the spleen completely mobile on its pedicle. A small blood vessel often runs from the upper pole of the spleen to the other splenic vessels and this was ligated and divided to mobilize the organ fully. The muscle of the abdominal wall was then gently split in the left flank over a distance of about $0.5 \mathrm{~cm}$ and the spleen passed from the abdomen through this narrow muscular split, to allow it to lie subcutaneously (Fig. 1). The margin of the splenic mesentery was secured to the muscle wall with three stitches of 7-0 silk. Three interrupted catgut sutures were placed between the subcutaneous tissue and the muscle wall on the medial side of the spleen to create a subcutaneous pocket. The abdomen was closed using a continuous catgut suture for the muscle layer and a subcuticular suture of catgut for the skin.

\section{Partial hepatectomy}

Partial hepatectomy was carried out by the method of Higgins and Anderson (1931). 


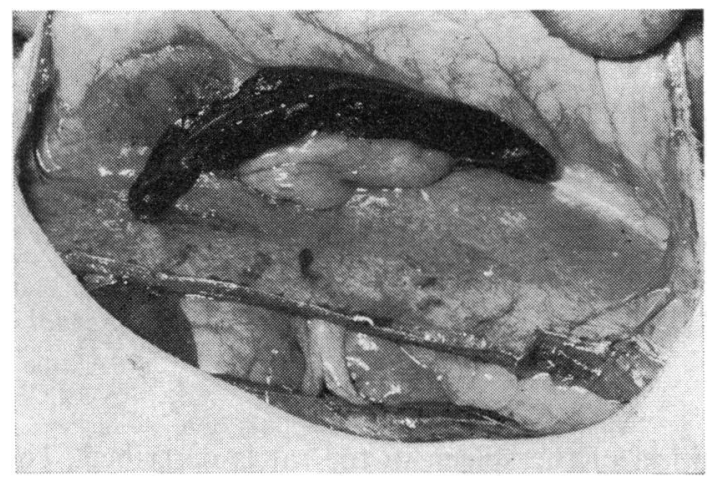

Fig. 1 Transposed spleen lying in the subcutaneous plane in the left flank.

\section{CLEARANCE STUDIES}

The clearance of radioactive compound from the splenic pulp was measured in 44 animals at times between one day and four weeks after subcutaneous transposition of the spleen. This experiment was performed with three compounds: saline solution of xenon 133, sodium pertechnetate $\left(\mathrm{Na}^{99} \mathrm{Tc}^{\mathrm{m}} \mathrm{O}_{4}\right)$, and human serum albumin labelled with iodine 125 .

The animals were anaesthetized and strapped in a supine position. The skin over the spleen was incised and the spleen gently exposed with scissors. A paediatric scalp vein needle (size 21) was gently inserted into the splenic pulp in the long axis of the spleen and was secured in position with a catgut suture passed through the incised skin edge. Lead shielding, through which transmission of radiation was negligible, was placed over and in close proximity to the animal. In this shielding was an aperture approximating to an ellipse $1.5 \mathrm{~cm} \times 3$ $\mathrm{cm}$ through which the spleen was exposed. A conventional scintillation detector with a crystal $5 \mathrm{~cm}$ in diameter $\times 2.5 \mathrm{~cm}$ thick was positioned over the spleen. A parallel collimator $2.5 \mathrm{~cm}$ deep was used and placed almost in contact with the lead shield. The radioactive material was injected and the counts, after pulse height analysis, were recorded on a printer fed from a scaler-timer. Counts were recorded every second for the first 40 seconds and then every 10 seconds for 150 seconds, except for the studies with xenon in which counts were continued for a further 150 seconds. With ${ }^{125}$ I-labelled human albumin equilibrium was quickly established. Residual counts remained constant and were subtracted from the counts for subsequent injections in the same animal. The pertechnetate took considerably longer to reach equilibrium but it was established before subsequent injections were made and again the residual counts were subtracted. Xenon, which is removed by the lungs, never reaches equilibrium.
Counts were therefore allowed to fall below $10 \%$ of the initial value before proceeding to further injections and no subtraction was made for residual activity. The corrected counts were then plotted on semi-logarithmic graph paper.

In all cases an activity of $10 \mu \mathrm{Ci}$ was injected, initially in a volume of $0.5 \mathrm{ml}$, but as it was necessary to inject this over one to three seconds the early fast clearance was invalidated and the volume was reduced to $0.1 \mathrm{ml}$ injected in well under one second.

In addition, measurements were carried out during the collateral detection studies (see below) in which the disappearance curve was obtained from 40 to 250 seconds after injection. This was done by rearranging the lead shielding and detector to count over the spleen after the collateral detection part of the experiment was completed.

\section{DETECTION OF COLLATERAL CIRCULATION}

In 16 animals operated on between one day and four weeks previously, an attempt was made to detect porta-systemic venous communications which radiographic studies with splenoportography had led us to expect (Bengmark et al, 1970; McLachlan, Blumgart, and Roberts, 1971). The animals were prepared in the same way as for the clearance studies except that the shielding was rearranged to expose the axilla or groin of the rat. In one experiment the lead shielding used for the clearance studies was used so that only a small ellipse of the rat's skin was exposed. In the second experiment a much larger area was exposed by means of two pieces of lead, the edges of which were at right angles, one being adjusted laterally and the other longitudinally to expose the desired area. Care was taken to exclude the spleen, the needle, and the tubing from the field of view of the detector. Initially $0.5 \mathrm{ml}$ of saline solution of xenon 133 was injected over a period of two to three seconds, but for most of the animals, as in the case of the clearance studies, the volume was reduced to $0.1 \mathrm{ml}$. The detector and recording apparatus were as described for the clearance studies. Counts were collected for periods of one second up to a total of 40 seconds, averaged over two seconds, the background was subtracted and the result plotted on linear graph paper (Fig. 2). Only about the first 10 seconds are critical because whether collateral vessels were present or not was judged on the basis of the initial sharp rise. Splenoportography was then performed by hand injection of radioopaque water-soluble contrast medium through the same intrasplenic needles. A single radiograph was exposed during injection. Radiographs were interpreted by the radiologist (M.S.F.M.) and the isotopic results by the physicist (K.G.L.) independently. Results were then compared. 


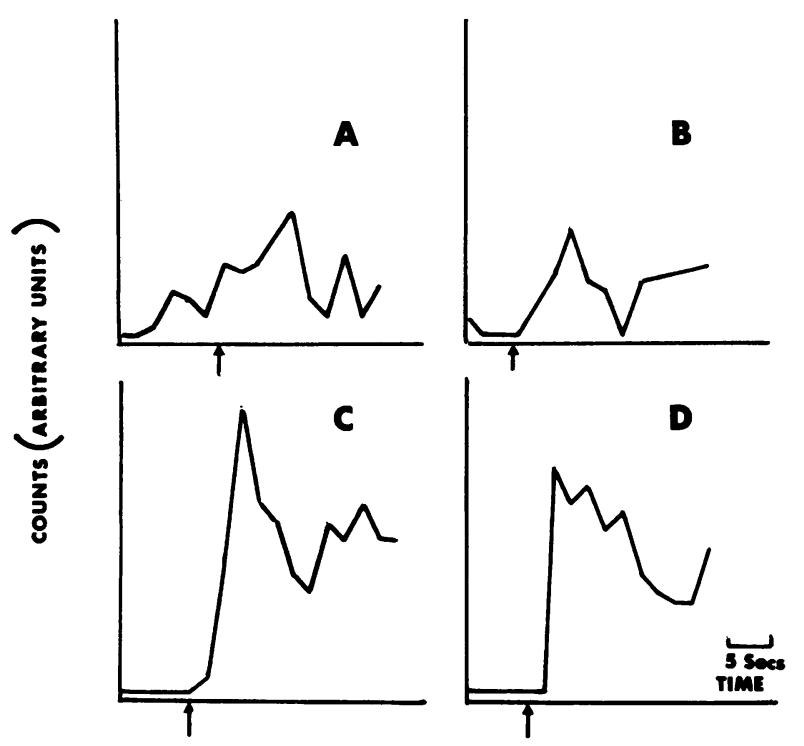

Fig. 2 Plots of radioactivity detected over the groin. The upper curves $(A$ and $B)$ are for control animals and the lower $(C$ and $D)$ are typical for animals in which collaterals had developed. Arrows indicate the time of injection.

\section{INFUSION TECHNIQUE}

Fresh rat serum was infused into the spleen of 15 animals on the day after splenic transposition. In five animals $5 \mathrm{ml}$ was infused over an hour. In the other 10 animals, five of which had undergone partial hepatectomy at the time of splenic transposition, $8 \mathrm{ml}$ was infused over one hour.

The animals were anaesthetized and strapped in a supine position. A needle was inserted in the long axis of the spleen as described for the collateral detection experiments. The needle was then connected to a syringe secured in a Palmer infusion pump and the rat serum infused. In three animals randomly selected, the position of the needle was checked by splenoportography performed as before. The needle was then withdrawn from the spleen and the skin incision closed.

\section{Results}

SURGICAL PROCEDURES

All the animals tolerated the operative procedures well and all survived.

SPLENIC CLEARANCE STUDIES

Typical examples of the clearance curves are shown in Figure 3. The first $\mathbf{4 0}$ seconds of the curves of the three compounds are shown in Fig. 3D and each appears to consist of a fast and a slow component. In this initial part of the curves albumin exhibits the fastest clearance and the xenon the slowest. Radioactivity cleared from the spleen into the general circulation will probably have influenced the counting rate before the completion of $\mathbf{4 0}$ seconds, particularly affecting the albumin curves, but no allowance has been made for this. Because of the slower clearance of the pertechnetate and consequent slower appearance of activity in the circulation it was possible to follow the curve further. This revealed a third still slower component. (Figure 3B shows the complete curve.) Xenon is a special case because of its highly efficient clearance by the lungs and recirculation is unimportant. This enabled the curve to be followed indefinitely and the xenon appears to be cleared completely by a component similar to the third pertechnetate one (Fig. 3A). Two measurements were made from the curves. First, the time $\left(\mathrm{C}_{\frac{1}{2}}\right)$ for the maximum initial counts to reach one half, and, secondly, the half time $\left(\mathrm{T} \frac{1}{2}\right)$ of the third component of the xenon and pertechnetate curves. The mean values of these parameters for the three compounds are summarized in Tables I and II.

The longest mean $\mathrm{C}_{2} \frac{1}{2}$ is for xenon (154 seconds) and the shortest for albumin (17 seconds) with the pertechnetate falling at an intermediate value (66 seconds). In no single instance was the $\mathrm{C}_{\frac{1}{2}}$ longer than five minutes.

The pertechnetate and xenon continued to be cleared although more slowly, as shown by the third components. Xenon has the shorter overall $\mathrm{T} \frac{1}{2}$ (174 seconds-mean of five groups tested) and petechnetate the longer (279 seconds).

\section{DETECTION OF COLLATERAL CIRCULATION}

The radioactivity which very quickly reaches the heart and lungs makes it impossible to determine isotopically whether collateral circulation has developed to the axilla.

Although there was some rise in the count rate over the groin when no collaterals were present (Figs. 2A and B) the rise was much sharper and more pronounced in animals in which collateral circulation was judged to be established (Figs. $2 \mathrm{C}$ and D). The height of the curves (Figs. $2 \mathrm{C}$ and $\mathrm{D}$ show curves of average height) may be related to the degree of collateral drainage but we have considered only whether collateral circulation was or was not present. For this the critical factor appears to be the sharpness of the rise.

In the two animals in which splenic transposition had been carried out on the day before testing no collateral circulation was detected by either the radiological (Fig. 4) or isotopic method (Figs. 2A and $B$ ). 

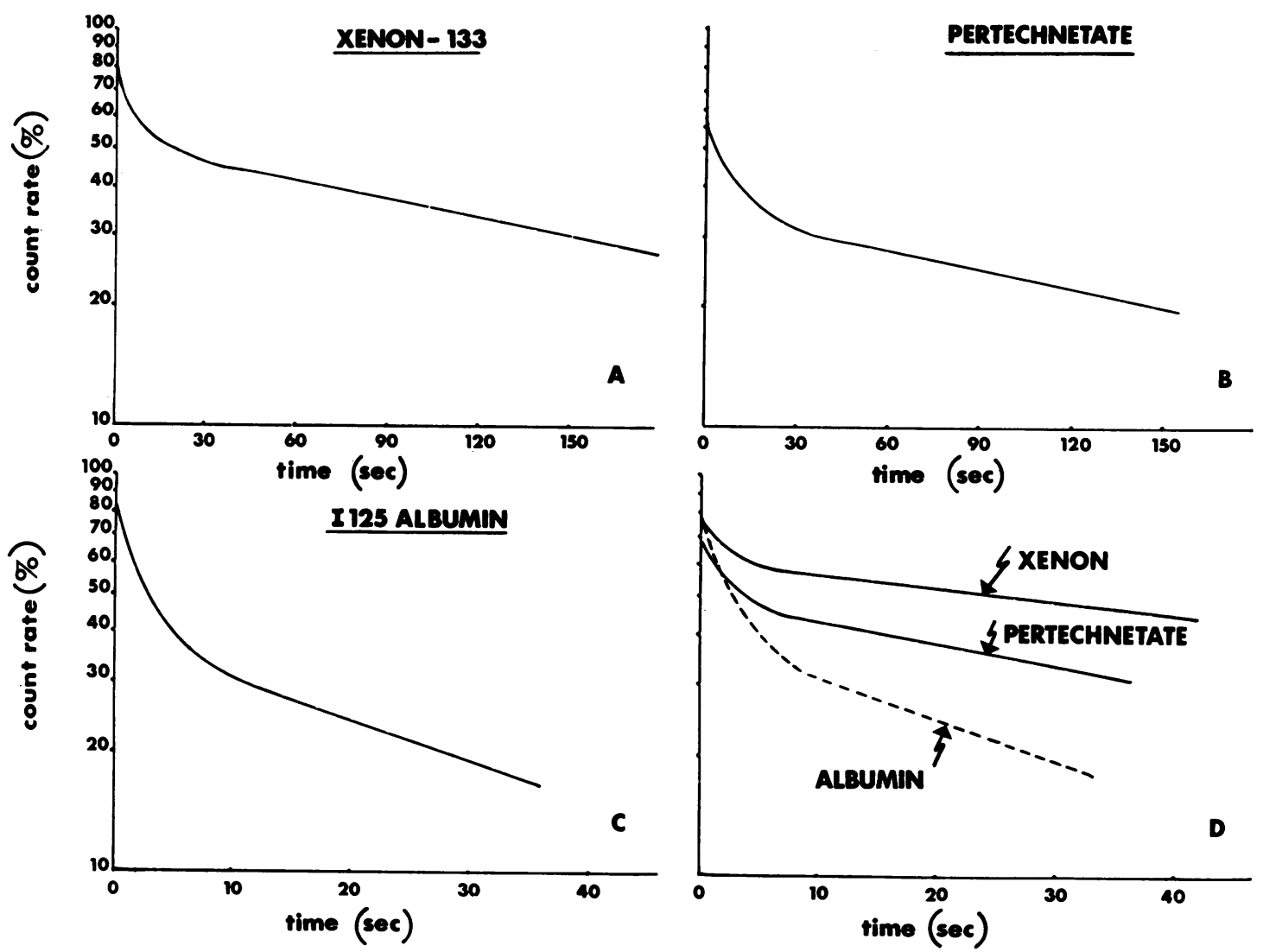

Fig. 3 Clearance curves for radioactive substances injected intrasplenically. A to $C$ show the complete curves for xenon, pertechnetate, and albumin. D shows a comparison between early parts of the three curves.

\begin{tabular}{llclll}
\hline Time after Operation (days) & Number of Animals & Number of Injections & $\begin{array}{l}\text { Volume of Injection } \\
(\mathrm{m})\end{array}$ & $\begin{array}{c}\text { Mean } \pm S D \text { for } \\
T \frac{1}{2}(\mathrm{sec})^{1}\end{array}$ & $\begin{array}{c}\text { Mean } \pm S D \text { for } \\
C \frac{1}{2}(\mathrm{sec})\end{array}$ \\
\hline 1 & 3 & 17 & $0 \cdot 5$ & $144 \pm 28$ & $113 \pm 13$ \\
1 & 8 & 24 & $0 \cdot 1$ & $215 \pm 58$ & $154 \pm 70$ \\
5 & 5 & 28 & $0 \cdot 5$ & $193 \pm 61$ & $140 \pm 52$ \\
$16-25$ & 5 & 5 & $0 \cdot 1$ & $142 \pm 25$ & No early values $^{1}$ \\
28 & 8 & 8 & $0 \cdot 1$ & $178 \pm 27$ & No early values $^{1}$ \\
\hline
\end{tabular}

Table I ${ }^{133}$ Xenon clearance

${ }^{1} \mathrm{~T} \frac{1}{2}$ values obtained during collateral detection experiments.

\begin{tabular}{lllllll}
\hline Compound & $\begin{array}{l}\text { Time after } \\
\text { Operation (days) }\end{array}$ & $\begin{array}{l}\text { Number of } \\
\text { Animals }\end{array}$ & $\begin{array}{l}\text { Number of } \\
\text { Injections }\end{array}$ & $\begin{array}{l}\text { Volume of } \\
\text { Injection }(m)\end{array}$ & $\begin{array}{l}\text { Mean } \pm \text { SD for } \\
\text { T(sec) }\end{array}$ & $\begin{array}{l}\text { Mean } \pm S D \text { for } \\
\text { C }\end{array}$ \\
\hline Pertechnetate & 1 & 6 & 21 & $0 \cdot 1$ & $279 \pm 96$ & $66 \pm 13$ \\
Albumin & 1 & 9 & 22 & $0 \cdot 1$ & - & $17 \pm 9$ \\
\hline
\end{tabular}

Table II Albumin and pertechnetate clearances 


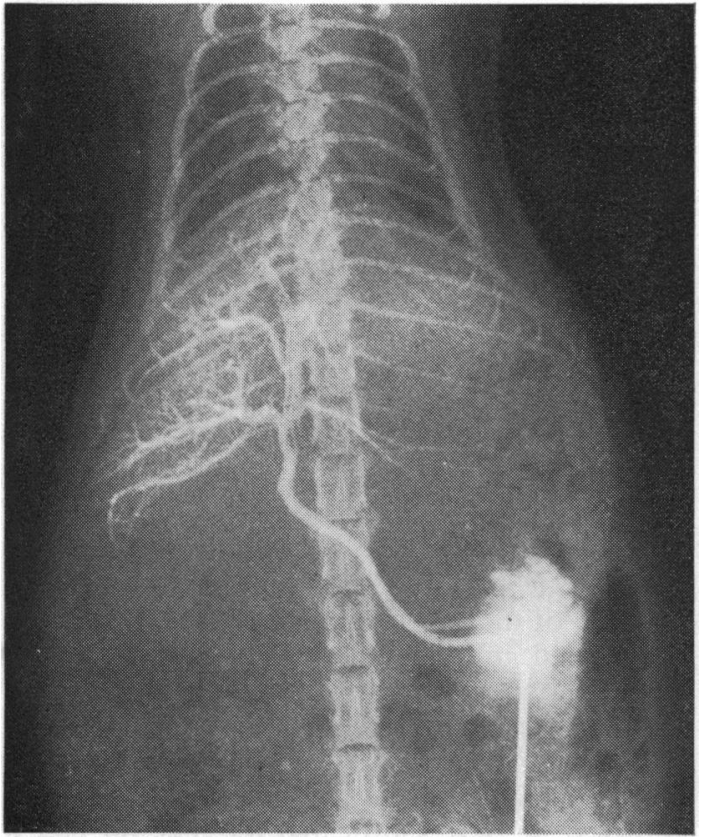

Fig. 4.

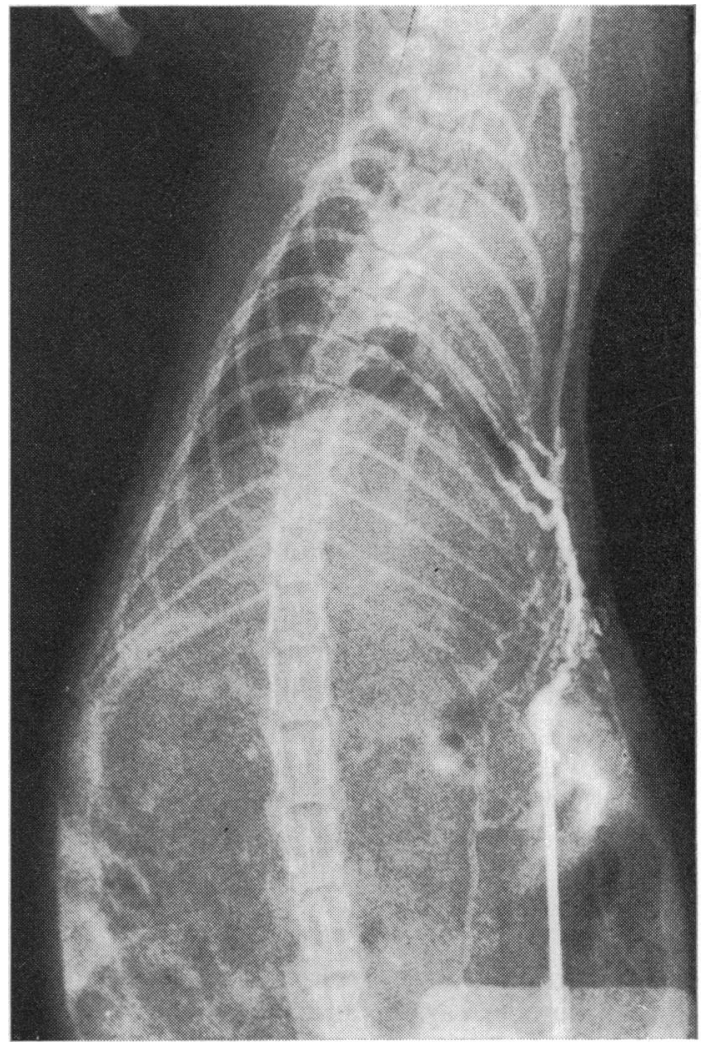

Fig. 6.

Fig. 4 Splenoportography. Contrast injected into splenic pulp outlines splenic and portal veins, including fine intrahepatic vessels.

Fig. 5 A large collateral vein runs from the spleen to the left groin.

Fig. 6 Portal vein tied after development of collateral veins. A large vein runs cranially along the lateral chest wall. Several large intercostal veins are shown. Smaller systemic veins run caudally. No filling of portal system.

Fig. 5. 
Six of the 14 rats operated on from 18 days to four weeks previously had axillary collateral circulation and 10 had collateral vessels to the groin demonstrated by splenoportography (Fig. 5). The isotopic method detected collateral vessels to the groin in 12 of these 14 animals. Overall there was agreement between the two methods in the demonstration of collateral circulation to the groin in 12 of the 16 cases. An analysis of the comparison is shown in Table III.

\begin{tabular}{lllll}
\hline Isotopic & + & - & + & - \\
Radiographic & + & - & - & + \\
No. of animals & 9 & 3 & 3 & 1 \\
\hline
\end{tabular}

Table III Comparison of radiographic and isotopic methods for the detection of collateral vessels to the groin

+ Collaterals demonstrated

- No collaterals demonstrated

The presence of groin collaterals detected by the radioisotopic method is a reliable indication that porta-systemic communications exist. This was confirmed in four animals in which porta-systemic connexions had been demonstrated by the isotopic method. The portal veins of these animals were tied at a second operation and all have survived for three months. The portal venous drainage in these animals was entirely via the porta-systemic communications (Fig. 6).

\section{INFUSION STUDIES}

All the animals tolerated the infusions of fresh rat serum and all survived. Thus even the partially hepatectomized rat will tolerate portal infusions of large volume as early as one day after operation.

\section{Discussion}

The potential experimental value of gaining direct access to the portal circulation in the intact animal stimulated the development of the technique reported here. Bengmark et al (1970) first developed a method for subcutaneous splenic transposition in the rat and hoped to use the preparation for the introduction of oncolytic agents into the portal circulation. However, they found that when they first carried out splenoportography three weeks postoperatively a rich network of porta-systemic communications had developed. Indeed, the development of this collateral circulation was so extensive that it prevented satisfactory opacification of the portal vein on splenoportography. They concluded that the method was of limited value as a technique for transplenic portal injection.

The surgical technique described by these authors differs from ours. Instead of the spleen being brought to the surface through a muscle-cutting incision in the left flank, we have passed it into a subcutaneous position through a small muscle-splitting wound separate from the main abdominal incision. Although collateral venous connexions between the spleen and the systemic veins develop in all rats, a splenohepatic venous circulation still exists (McLachlan et al, 1971). The method offers a reliable means of portal venous injection during the first 10 postoperative days. After this time the chance of leakage into the systemic circulation increases, particularly if repeated intrasplenic injections have been made in the interval. However, in some animals collateral veins may still not be demonstrable seven weeks after operation (McLachlan et al, 1971).

The clearance studies were designed solely to demonstrate that different substances injected into the pulp of the transposed spleen were cleared and not pooled in the organ. This has been amply demonstrated and no further analysis of the results was felt to be necessary.

Although the values for $T_{\frac{1}{2}}$ and $\mathrm{C}_{\frac{1}{2}}$ were significantly different between the compounds $(P<0.01$ in all cases) we have shown that the time for half the activity to be cleared never exceeded five minutes and that the clearance continued after this time. Differences between the compounds were to be expected since they varied considerably, being a soluble inert gas, a crystalloid compound, and a macromolecular protein. The latter, since it is unlikely to diffuse readily, could be predicted to clear quickly. The other two diffuse rapidly through the organ and would be expected to clear more slowly. This is confirmed by the results obtained for $C_{\frac{1}{2}}$.

A subsidiary objective of the experiment was to see whether the clearance varied with the length of time that had elapsed after splenic transposition. Although there are statistically significant differences between the xenon values of $T_{\frac{1}{2}}$ and $\mathrm{C}_{\frac{1}{2}}$ at different postoperative times, no consistent pattern emerges.

Knowledge of the development of subcutaneous porta-systemic communications seemed to depend on their radiological demonstration. We have attempted to show whether collateral circulation could be detected by isotopic methods. Although our results make it clear that the isotopic method could not detect axillary collateral vessels, it proved highly sensitive in the detection of collateral circulation to the groin. It might be expected that the isotopic technique would be more sensitive than the radiographic technique in that a very small or diffuse collateral circulation not visible radiographically might be detected with the very sensitive scintillation detector. In only one animal were collateral vessels to the groin shown radiographically and not isotopically, and it is interesting to 
note that this result was found in the one experiment in which the smaller area of skin was exposed. It is conceivable that this result may have been positive on isotopic testing if a larger area of skin had been exposed in this animal as it was in the later experiments. In contrast, the isotopic method indicated collateral vessels in three animals in which none were demonstrated radiologically. This may have been due to the greater sensitivity of the method but, since these three results were obtained during experiments with a larger area of skin exposed, it is difficult to exclude the possibility that the spleen may have been incompletely shielded, yielding a falsely positive result. The isotopic method thus offers a means of screening animals postoperatively for definite evidence of collateral circulation to the groin but is of no value in its detection in the axilla.

It is significant that in four animals screened for the presence of collaterals in the groin by the isotopic method, the portal vein was successfully tied at a subsequent operation and the animals survived. This confirms the observation (Bengmark et al, 1970) that subcutaneous transposition of the spleen in the rat can be used as a means of portasystemic diversion.

The infusion experiments demonstrate that large volumes can be infused into the portal circulation of the rat. The method described in this communication is simple and all the animals survived without any obvious ill effects.

\begin{abstract}
References
Bengmark, S., Börjesson, B., Olin, T., Sakuma, S., and Vosmic, J. (1970). Subcutaneous transposition of the spleen-an experimental study in the rat. Scand.J. Gastroent.,5, Suppl. 7, 175-179.

Higgins, G. M., and Anderson, R. M. (1931). Experimental pathology of the liver. I. Restoration of the liver of the white rat following partial surgical removal. Arch. Path., 12, 186-202.

McLachlan, M. S. F., Blumgart, L. H., and Roberts, E. E. (1971). Spleno-portography in the rat. (Submitted for publication.)
\end{abstract}

\section{The June 1971 Issue}

\section{THE JUNE 1971 ISSUE CONTAINS THE FOLLOWING PAPERS}

The action of metoclopramide on human gastroduodenal motility A. G. JOHNSON

Ileo-rectal anastomosis for Crohn's disease of the colon W. N. W. BAKER

The fate of ileorectal anastomosis in Crohn's disease J. H. BURMAN, w. T. COOKE, AND J. ALEXANDER WILLIAMS

Absorption studies in patients with 'intraabdominal ileostomy reservoirs' and in patients with conventional ileostomies R. JAGENBURG, G. DOTEVALL, J. KEWENTER, N. G. KOCK, AND B. PHILIPSON

Finger clubbing and regional enteritis J. F. FIELDING AND $\mathrm{W}$. T. COOKE

Changes in structure and peptidase activity of rat small intestine induced by prednisolone ALFRED J. WALL AND T. J. PETERS

A trial of deglycyrrhizinated liquorice in the treatment of duodenal ulcer H. FELDMAN AND T. GILAT
Psychological significance of the irritable colon syndrome I. G. HISLOP

Controlled study of autoimmunization against liver in inbred rat strains B. P. MACLAURIN

ABO blood groups in patients with gastric carcinoma associated with pernicious anaemia SHEILA CALlender, M. J. S. LANGMAN, I. N. MACLEOD, J. MOSBECH, AND K. RAHTKENS NIELSEN

Polyps of the rectum and colon F. POTET AND J. SOULLARD

Progress report Pathogenesis of amoebiasis R. A. NEAL

Progress report Bacteria and disease of the biliary tract ALISTER J. SCOTT

British Society of Gastroenterology

Notes on books

Notes and activities

Copies are still available and may be obtained from the PUBLISHING MANAGER, BRITISH MEDICAL ASSOCIATION, TAVISTOCK SQUARE, LONDON, WC1H 9JR, price $87 \frac{1}{2} \mathrm{P}$ 